\title{
Effect of Complementary Split Ring Resonator Structure on PIFA Antenna
}

\author{
Nizar Sghaier ${ }^{1}$, Lassaad Latrach ${ }^{1}$ and Ali Gharsallah ${ }^{1}$ \\ ${ }^{l}$ Unit of Research Circuits and Electronics Systems HF, \\ Faculty of Science, departement Electronics \\ University El Manar Tunis, Tunisia \\ sghaier.nizar0@gmail.com
}

\begin{abstract}
This paper proposes a new design of Planar Inverted-F Antenna with complementary split ring resonators (CSRRs). The operating frequency of this antenna is $2.425 \mathrm{GHz}$ for Wireless Local Area Network (WLAN) application. The method is to incorporate a single CSRR cell and a periodic array CSRRs on the radiating patch. We studied the effect of this method on the characteristics of antenna in free space and in the presence of the user. We used a homogeneous model of a human head near our antenna. The parameters that considered in these works are gain, electric field, magnetic field, return loss, radiation pattern, power loss density and Specific Absorption Rate. The addition of CSRRs on to PIFA antenna will improve the gain from $4.76 \mathrm{~dB}$ to $4.81 \mathrm{~dB}$ and will reduce the Specific Absorption Rate from 3.57 W/kg to 2.95 W/kg.
\end{abstract}

Index Terms - Complementary Split ring resonators, Gain, Specific Absorption Rate, Wireless Local Area Network.

\section{INTRODUCTION}

Wireless communications have progressed very rapidly in recent years, and researchers began working on miniaturization and improved antennas and reduce the value of the specific absorption rate. The EM absorption in the human head from the radiated antenna on a mobile phone is measured in terms of the specific absorption rate (SAR), which is defined as the power absorbed by a unit mass of body tissue [1]. The mass measured for SAR evaluation corresponds to a mass of $1 \mathrm{~g}$ or a mass of $10 \mathrm{~g}$ of body tissue. Various techniques have been discussed in the last decade to reduce of the Specific Absorption Rate (SAR) of cellular phone. Kusuma AH, et al [2] was proposed, a novel structure of PIFA with an additional thin metal shim-layer in between the patch and the chassis with conducting sidewalls attached at the free-sides of the antenna. Il Kwak S, et al was used [3], a two patch EBG structure as an additional antenna element. Faruque MRI, et al [4] was used, a triangularshaped split ring resonator (SRR) surface in between the PIFA and the human head to reduce the SAR at GSM $900 \mathrm{MHz}$. To meet the miniaturization requirement, the antennas employed in mobile terminals must have their dimensions reduced accordingly. The methods of improvement and miniaturization of antennas have appeared ago the evolution of communications technology [5]. In the literature, these methods are divided into three classes. The first class is devoted to the methods that 
use the geometry of the radiating element as the geometry fractal and refolding[6-7].The second class includes methods that use the concept of high permittivity substrates [8]. In the third class, includes methods that use metamaterials that can be metallic metamaterials or complementary metamaterials. In this paper, a new approach of a complementary split ring resonator (CSRR) PIFA antenna is introduced to reduce the SAR in the human head and the size of PIFA antenna. This manuscript is divided into three parts, the first part is devoted to the presentation of the antenna characteristics. The second part is specified to describe the influence of CSRRs on antenna parameters[9-10]. And we finished with a demonstration to confirm our results.

\section{PIFA ANTENNA WITHOUT COMPLEMENTARY SPLIT RING RESONATORS}

The PIFA antenna studied, Figure 1 is composed by a rectangular radiating patch witch length is $L_{p}=10 \mathrm{~mm}$ and width $W_{p}=16 \mathrm{~mm}$. The patch is placed at a height $\mathrm{h}$ from the ground plane. The last has a length $L_{m}=100 \mathrm{~mm}$ and a width $W_{m}=40 \mathrm{~mm}$. The patch is matched to the ground plan via a rectangular shorting plate. The shorting plate has a width $W_{c}=0.5 \mathrm{~mm}$ and a length $L_{c}=H=8 \mathrm{~mm}$. The patch is integrated on a dielectric substrate such FR-4 having a relative constant dielectric $\varepsilon_{\mathrm{r}}$ equal to 4.3 , a relative permeability $\mu_{r}$ equal to 1 , a loss tangent $\tan \delta$ equal to 0.0018 (cont.fit) and a thickness $H_{s}$ equal to $1.2 \mathrm{~mm}$. The PIFA antenna is fed by a coaxial cable of excitation having a characteristic impedance $Z_{c}$ equal to $50 \Omega$. The distance between the power supply and the shorting plate is $D_{a}=5 \mathrm{~mm}$.

The geometric parameters of the patch antenna, shown in Figure 1 are determined from the following equations [10]:

$$
F_{r}=\frac{c_{0}}{4 \sqrt{\varepsilon_{r}}\left(L_{p}+W_{p}-W_{s}\right)}
$$

where $c_{0}$ is the speed of light,

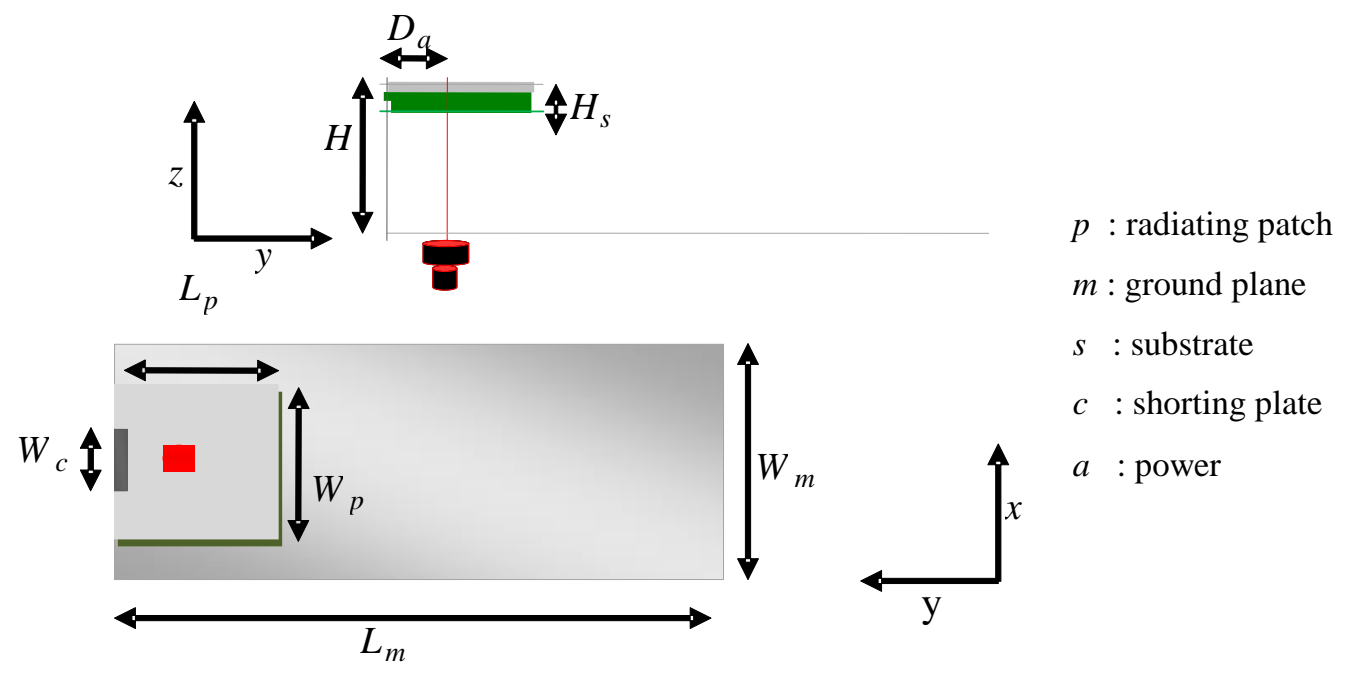

Fig. 1. Parameters geometric of PIFA antenna.

The effective permittivity: 


$$
\varepsilon_{e}=\left[1+\left(\frac{H_{S}}{H-H_{S}}\left(a_{1}-b_{1} \ln \frac{w}{H-H_{S}}\right)\left(\frac{1}{\sqrt{\varepsilon_{r}}}\right)-1\right)\right]^{-1}
$$

where:

$$
\begin{gathered}
a_{1}=\left(0.8621-(0.1251) \ln \left(\frac{H_{S}}{H-H_{S}}\right)\right)^{4} \\
b_{1}=\left(0.4986-(0.1397) \ln \left(\frac{H_{S}}{H-H_{S}}\right)\right)^{4} \\
w \square 1
\end{gathered}
$$

\section{RESULTS AND DISCUSSION}

Figure 2 shows the fabricated PIFA antenna.

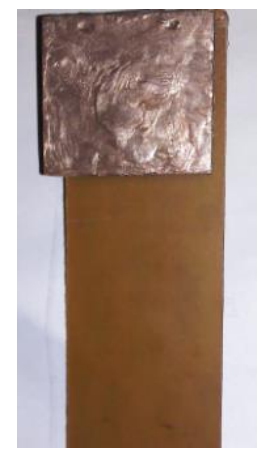

Fig. 2. Photograph of the realized PIFA antenna.

The measured and simulated $S_{11}$ of the proposed antenna are simultaneously illustrated in Fig. 3. It is clearly seen that the measured and computed $S_{11}$ are in excellent agreement with each. Such an excellent agreement between measured and simulated results indicates the high tolerance of this antenna in terms of dimensions and materials.

From the measured results, we note that our PIFA antenna having a resonant frequency equal to $2.425 \mathrm{GHz}$ with a return loss $\mathrm{S}_{11}$ equal to $-25.15 \mathrm{~dB}$ and a frequency band $B_{f}$ equal to $529 \mathrm{MHz}$ measured at $-10 \mathrm{~dB}$.

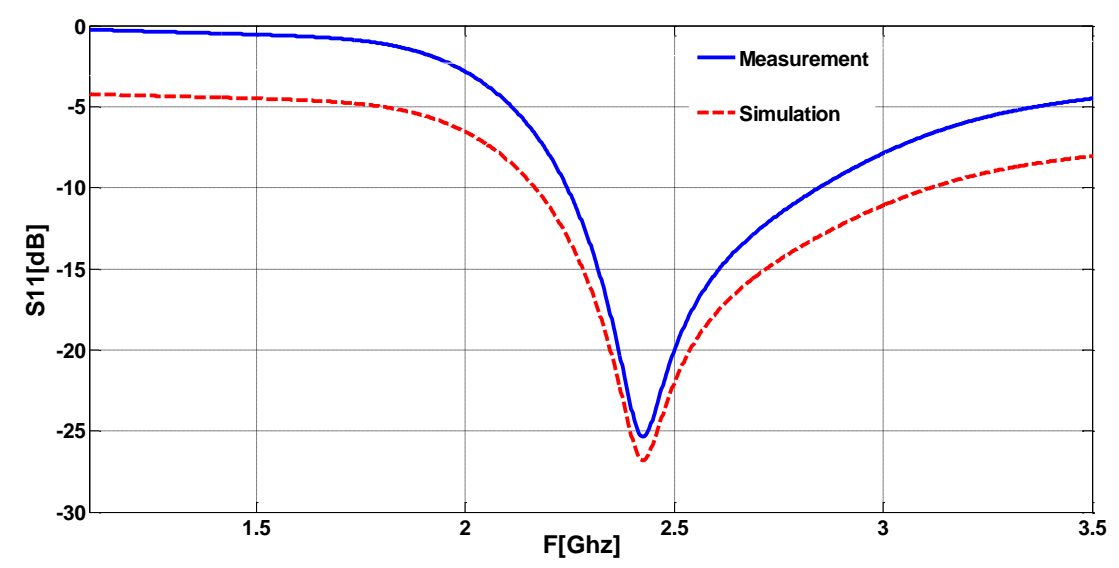

Fig. 3. Measured and simulated return loss characteristic of Antenna. 
Figure 4 indicates the measured and simulated gain versus $\theta$ at one selected frequencies, $2.425 \mathrm{GHz}$. Thus, the reference antenna is characterized by a gain equal to $4 \mathrm{~dB}$ measured at $2.425 \mathrm{GHz}$.

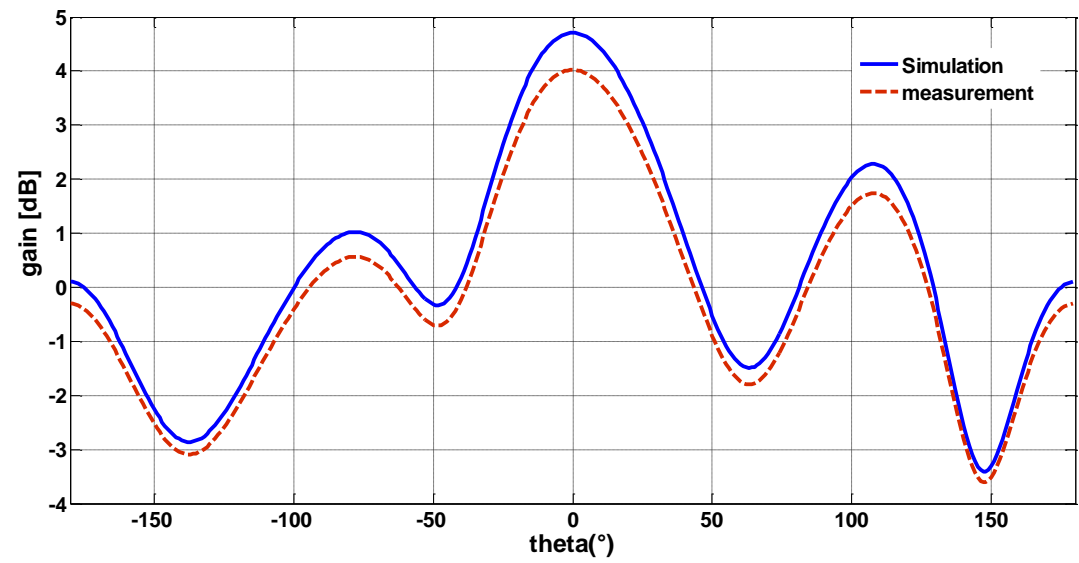

Fig. 4. Radiation pattern of PIFA Antenna, to calculate the gain

Figure 5 shows the measured and simulated antenna efficiency of the antenna versus frequency for the proposed PIFA antenna.

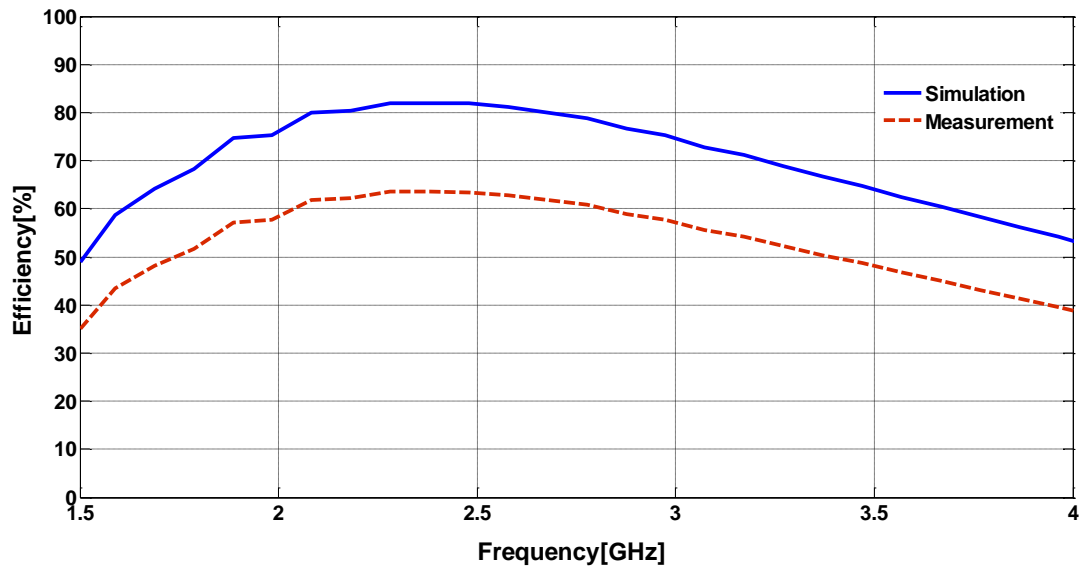

Fig. 5. Radiation pattern of PIFA Antenna, to calculate the efficiency.

\section{PIFA ANTENNA WITH COMPLEMENTARY SPLIT RING RESONATORS}

The study of the integration of complementary metamaterials with PIFA [11] antenna is based on two interesting parts: the first is devoted to use one additional element of a complementary split ring resonator having a fixed position in the middle of the radiating patch The objective of is to extract the best results. The second part is the extension of the previous study, the complementary metamaterials used are presented by a homogeneous and periodic array of split ring resonators. This array has the same position as the reference case of the PIFA antenna found in the previous section.

The different structures of CSRR PIFA antenna are shown in Fig .6, the elementary cell of CSRR geometric feature having a diameter as equal to $3 \mathrm{~mm}$ ring, a track width of $1 \mathrm{~mm}$ and an opening ring of $1 \mathrm{~mm}$. The resonator CSRR is located in the middle of the radiating element in a manner parallel to the axis of the feeding. 


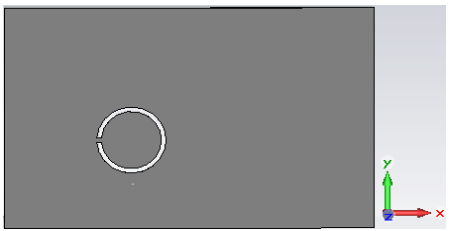

(a)

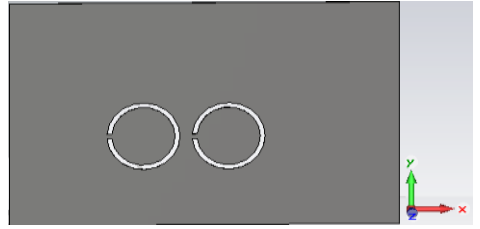

(b)

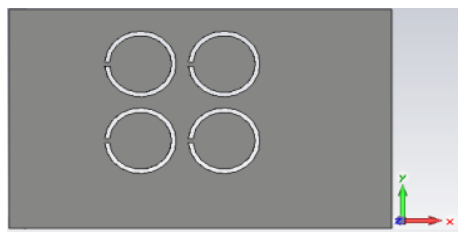

(c)

Fig. 6. PIFA antenna with present the CSRR: (a) inclusion of one cell CSRR, (b) inclusion of two CSRR and(c) inclusion of four elements of CSRR

\section{RESULTS AND DISCUSSION}

The simulation results collected by the CST Microwave Studio software is stored in Table 1 on the comparison of the characteristic parameters of patch antenna in the absence and presence metamaterials.

TABLE. 1 RESULT OF VARIOUS PERFORMANCE PARAMETERS OF THE PIFA ANTENNA IN THE PRESENCE OF CSRR.

\begin{tabular}{ccccccc}
\hline Structure & $\boldsymbol{f}_{\boldsymbol{r}}(\mathbf{G H z})$ & $\mathbf{S}_{\mathbf{1 1}}(\mathbf{d B})$ & $\mathbf{G a i n}(\mathbf{d B})$ & $\boldsymbol{E}_{\boldsymbol{m a x}}(\mathbf{V} / \mathbf{m})$ & $\boldsymbol{I}_{\boldsymbol{m a x}}(\mathbf{A} / \mathbf{m})$ & Efficiency $(\boldsymbol{\%})$ \\
\hline PIFA & 2.425 & -25.15 & 4 & 3289 & 21.2 & 81.2 \\
PIFA +1CSRR & 2.35 & -33.69 & 5.09 & 3989 & 31.2 & 94.2 \\
PIFA +2CSRR & 2.34 & -32.05 & 5.02 & 4676 & 46.2 & 82.4 \\
PIFA +4CSRR & 2.33 & -31.81 & 4.24 & 4888 & 46.3 & 75.2 \\
\hline
\end{tabular}

we note:

$f_{r}(\mathrm{GHz})$ : Resonant Frequency

$\mathrm{S}_{11}(\mathrm{~dB})$ : Return Loss

$E_{\max }(\mathrm{V} / \mathrm{m})$ : Hight Value of the electric field

$I_{\max }(\mathrm{A} / \mathrm{m})$ : Hight Value of the magnetic field

The number of cells is limited by the return loss of the antenna. Indeed, when we used six cells the value of $S_{11}$ becomes equal to $-12 \mathrm{~dB}$. From the simulation results we noticed at firstly moment the number of CSRR elements is inversely proportional to the resonant frequency, as indicated by the variation curve of the return loss shown in Fig .7.

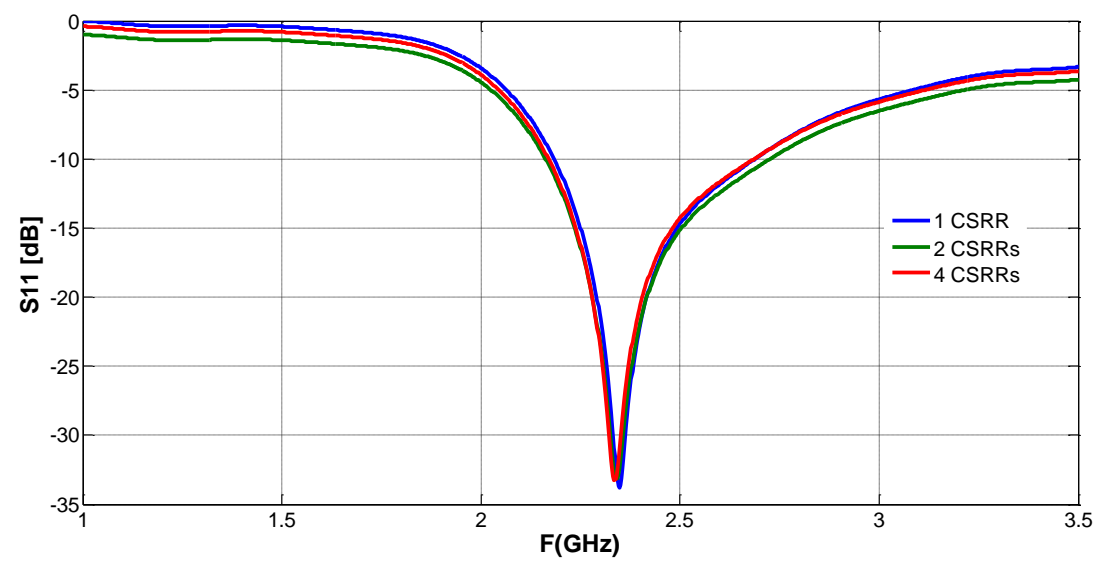

Fig. 7. Return loss of the PIFA antenna for various numbers of CSRR. 
We have noticed that adding SCRR cell reduces the resonant frequency and therefore the patch size reduction. Consequently, we observe clearly that excites a significant improvement between the one element of the CSRR course at remarkable values of return loss, gain, directivity and distributions of the electromagnetic field and the surface current of the antenna.

\section{MEASUREMENT RESULTS}

Figure 8 shows the fabricated PIFA antenna to use one additional element of a complementary split ring resonator. Considering the simple manufacturing facilities in our lab CSRR PIFA antenna, the structure is successfully constructed and measured.

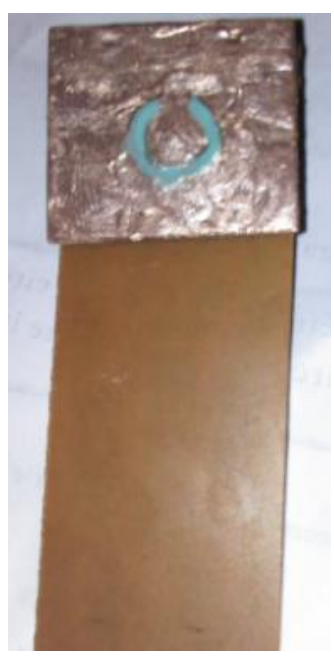

Fig. 8. Photograph of the realized CSRR PIFA antenna.

The measured and simulated $S_{11}$, gain and efficiency of the CSRR PIFA antenna are simultaneously illustrated in Fig. 9, 10, and 11. It is clearly seen that the measured and computed results are in excellent agreement with each. Such an excellent agreement between measured and simulated results indicates the high tolerance of this antenna in terms of dimensions and materials.

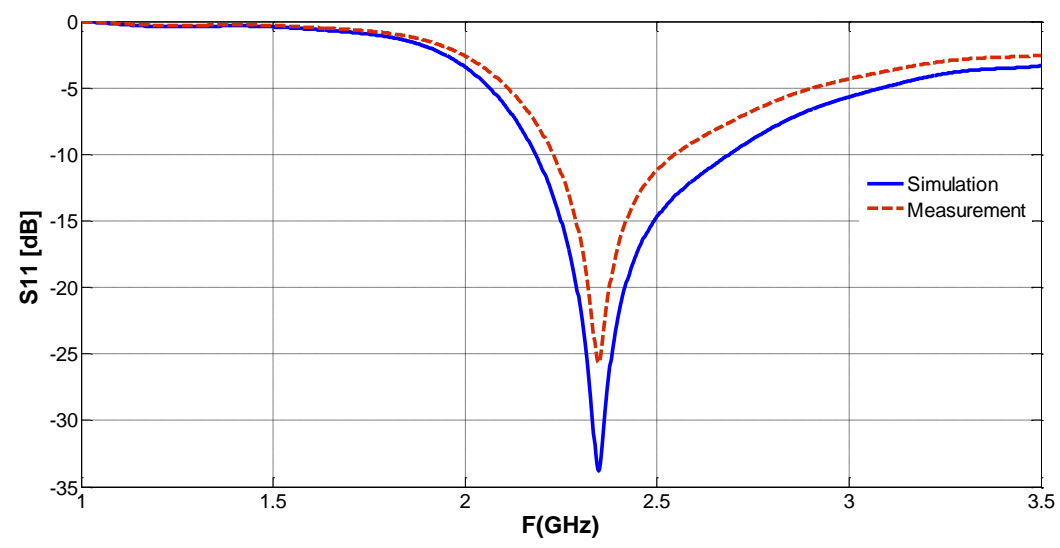

Fig. 9. Measured and simulated return loss of CSRR PIFA Antenna. 


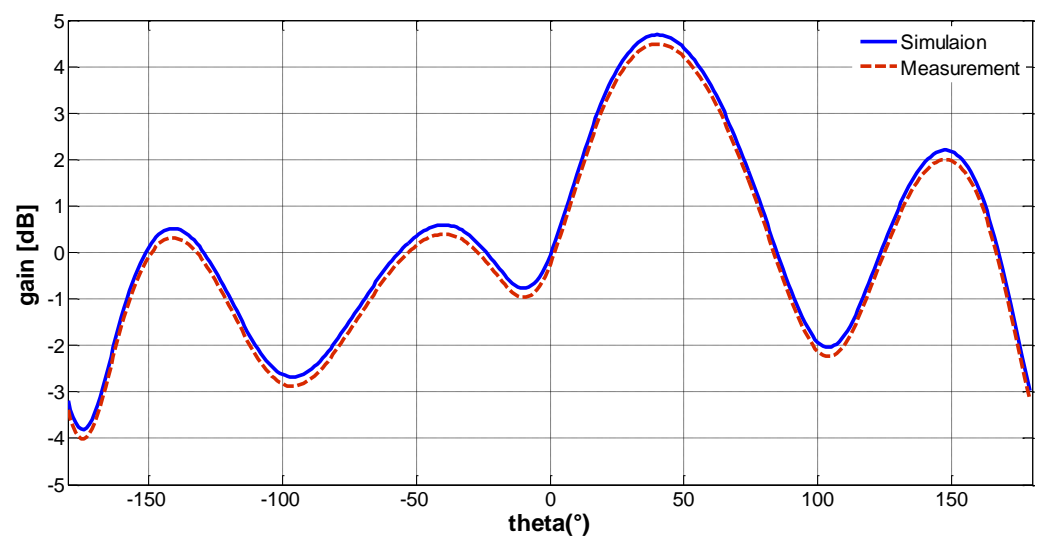

Fig. 10. Radiation pattern of CSRR PIFA Antenna, to calculate the gain.

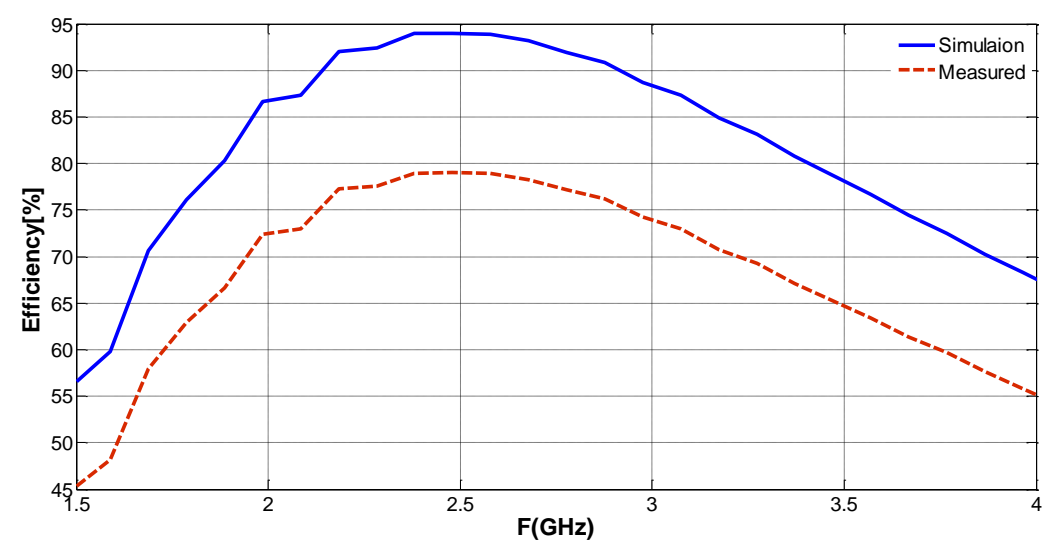

Fig. 11. Radiation pattern of PIFA Antenna, to calculate the efficiency.

\section{DEMONSTRATION}

\section{A. Power loss Density}

Principally the amplitudes of electric and magnetic fields radiated directly affect on the density of the total radiated power $p(r, \theta, \phi)$ of the antenna [12]. This radiated power is defined by the following equation:

$$
p(r, \theta, \phi)=\left|E_{\text {ray }}\right| \times\left|H_{\text {ray }}\right|=\frac{\left|E_{\text {ray }}\right|^{2}}{Z_{m}}
$$

where:

$$
\begin{array}{r}
\vec{E}_{r a y}=\frac{-d \vec{A}}{d t}-\operatorname{gra} \vec{d} V \\
\vec{H}_{r a y}=\frac{1}{\mu} \operatorname{rot} \vec{A} \\
Z_{m}=\frac{\left|E_{r a y}\right|}{\left|H_{r a y}\right|}
\end{array}
$$

Consequently, the total radiated power density $p(r, \theta, \phi)$ and particularly affects directly the characteristics of a radiating element as the radiation pattern, directivity, gain and antenna efficiency. So it is absolutely necessary to verify and demonstrate the need for the total radiated power density 
$p(r, \theta, \phi)$ is maximum in the case of the patch antenna with an elementary CSRR designed to validate and authenticate our approach. For this reason we offer Table 2 of measures the electromagnetic field radiated and total radiated power density for different structures the patch antenna in the absence and presence of complementary metamaterials.

Table.2 Measurements the Electromagnetic Field and the Total Radiated Power Density.

\begin{tabular}{ccccc}
\hline Structure & $\begin{array}{c}\boldsymbol{E}_{\text {ray }} \\
(\mathbf{V} / \mathbf{m})\end{array}$ & $\begin{array}{c}\boldsymbol{H}_{\text {ray }} \\
(\mathbf{A} / \mathbf{m})\end{array}$ & $\begin{array}{c}\boldsymbol{Z}_{\boldsymbol{m}} \\
(\boldsymbol{\Omega})\end{array}$ & $\begin{array}{c}\boldsymbol{p}(\boldsymbol{r}, \boldsymbol{\theta}, \boldsymbol{\phi}) \\
\left(\mathbf{m W} / \mathbf{m}^{2}\right)\end{array}$ \\
\hline PIFA & 9.4 & 0.025 & 376 & 235 \\
PIFA +1CSRR & 11.7 & 0.0311 & 376.2 & 363 \\
PIFA +2CSRR & 9.38 & 0.0249 & 376.7 & 233 \\
PIFA +4CSRR & 8.52 & 0.0226 & 377 & 192 \\
\hline
\end{tabular}

According to the results shown in the above table, we can show that the highest amplitudes of electric and magnetic fields radiated and total radiated power density are obtained for the metamaterials antenna structure which is composed of a PIFA antenna and a one complementary element of a split ring resonator. The latter structure allows us to amplify the total radiated power density to reach $363 \mathrm{~mW} / \mathrm{m}^{2}$ by an increase equal to $128 \mathrm{~mW} / \mathrm{m}^{2}$ than the PIFA antenna setting alone. Conversely, the technique of association of a unit cell CSRR with patch antenna is more efficient than the integration of a array CSRRs where the total radiated power density is reduced to $192 \mathrm{~mW} / \mathrm{m}^{2}$ by a degradation equal to $43 \mathrm{~mW} / \mathrm{m}^{2}$ compared to the reference case. The radiated power density for different structures is shown in Fig. 12.

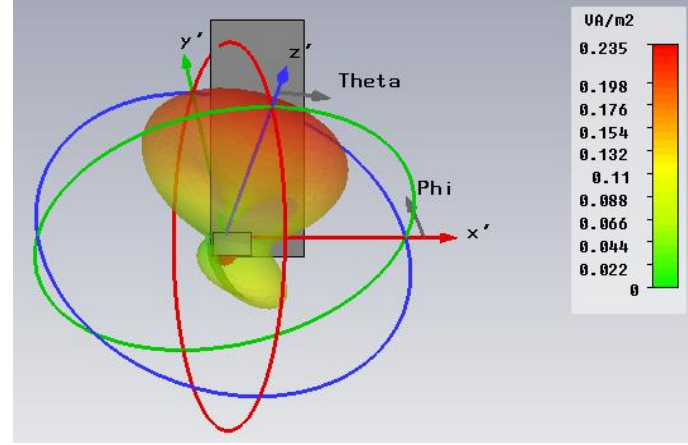

(a)

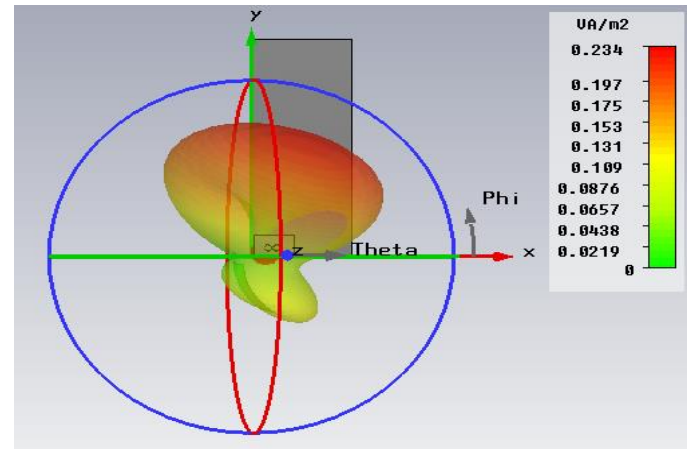

(c)

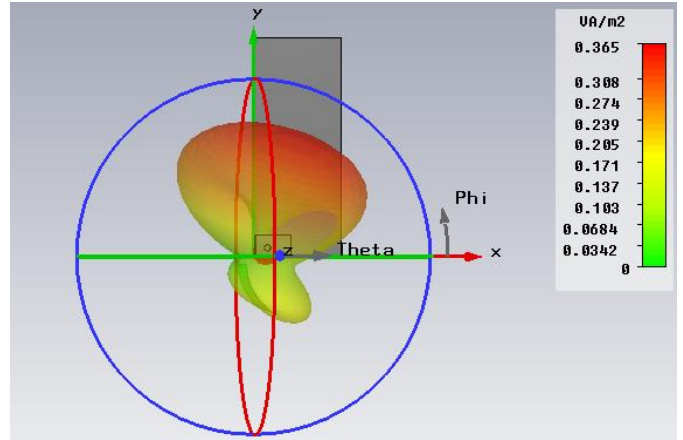

(b)

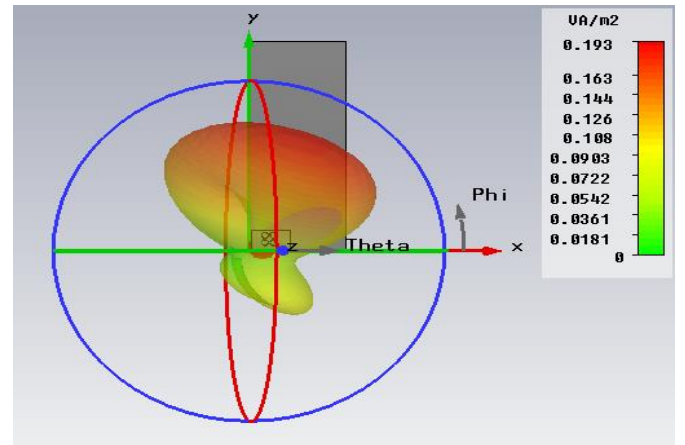

(d)

Fig. 12. Measure the total radiated power density: (a) PIFA alone, (b) PIFA with one CSRR, (c) PIFA with two CSRR and (d) PIFA with four CSRR. 


\section{B. The specific Absorption Rate}

The human head is represented by a homogeneous sphere of diameter equal to $200 \mathrm{~mm}$ and located at a distance equal to $10 \mathrm{~mm}$ of the antenna. The relative permittivity and electric conductivity of the human head tissues is achieved using Gabriel S. et al [13]. With the operating frequency of our antenna, the relative permittivity equal to 38.2 and the electric conductivity equal to $1.68[\mathrm{~S} / \mathrm{m}]$. The sphere having a volume element of giving density $\rho$ equal to 1000 .

The Specific Absorption Rate (SAR) is a defined parameter for evaluating the power absorbed in human tissue. It is given by equation (10):

$$
\mathrm{SAR}=\sigma|E|^{2} /(2 \rho)
$$

The Specific Absorption Rate (SAR) for with and without CSRR is presented successively in the following figures:

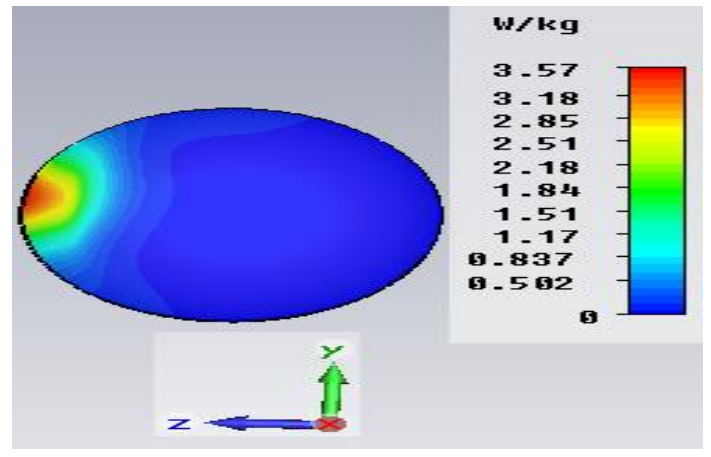

(a)

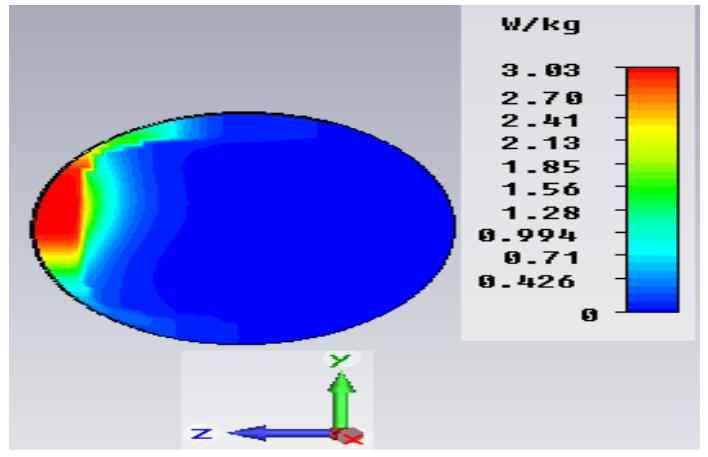

(c)

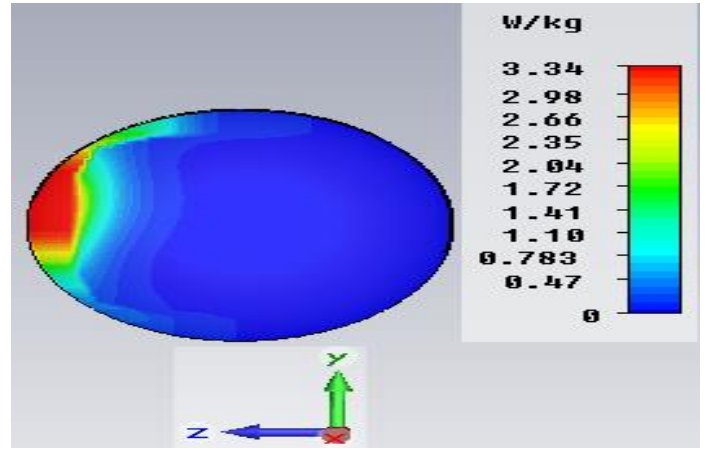

(b)

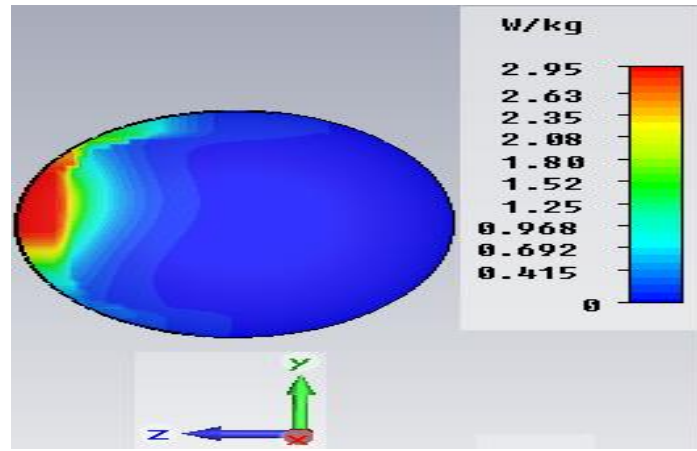

(d)

Fig. 13. The specific absorption rate: (a) without CSRR, (b) with one CSRR, (c) with two CSRR, (d) with four CSRR.

The maximum $10 \mathrm{~g}$ averaged SAR of the basic antenna structure and antenna with the proposed four CSRR structure is $3.57 \mathrm{~W} / \mathrm{kg}$ and $2.95 \mathrm{~W} / \mathrm{kg}$ at $2.425 \mathrm{GHz}$.

The simulation results are shown goods. In adding of CSRR decrease the electric field which ensures a reduction in SAR.

\section{CONCLUSION}

In this paper, a new approach of CSRR PIFA is proposed to reduce the peak SAR in the human head and the size of PIFA antenna. The patch of convention PIFA is modified using a cell of a complementary split ring resonator. The results indicate that the metamaterial CSRR improves an increase in the radiation 
efficiencies, gains and Power loss density. Moreover, the SAR results indicate significant reduction in the SAR values at the upper frequency band. Furthermore, future studies may be extended to develop metamaterial CSRR, which to apply this method in the multi-band antennas.

\section{ACKNOWLEDGMENT}

I would like to express my deepest thanks to Dr. Ali Gharsallah, my thesis Director.

\section{REFERENCES}

[1] Hossain MI, Faruque MRI, Islam MT. Analysis on the effect of the distances and inclination angles between human head and mobile phone on SAR. Progress in biophysics and molecular biology 119, no. 2, 103-110 doi: 10.1016 /j. pbiomolbio .2015.03.008. pmid:25863147, 2015.

[2] Kusuma AH, Sheta A-F, Elshafiey IM, Siddiqui Z, Alkanhal MA, Aldosari S, et al. A new low SAR antenna structure for wireless handset applications. Prog Electromagn Res;112: 23-40. doi: 10.2528/pier10101802, 2011

[3] Il Kwak S, Sim D-U, Kwon JH, Do Choi H. Comparison of the SAR in the human head using the EBG structures applied to a mobile handset. Microwave Conference, 2007 European. IEEE;. pp. 937-940, 2007.

[4] Hossain MI,Islam MT. Design of Miniaturized Double-Negative Material for Specific Absorption Rate Reduction in Human Head. PloS One.;9: e109947. doi: 10.1371/journal.pone.0109947. pmid:25350398, 2014.

[5] S. R. Best, "On the Performance Properties of the Koch Fractal and Other Bent Wire Monopoles", IEEE Transaction on Antenna and Propagation,p.1292, Vol. 51, No 6, June 2004.

[6] N. A. Saidatul, A. A. H. Azremi, R. B. Ahmad, P. J. Soh and F. Malek, 'multiband fractal planar inverted f antenna (fpifa) for mobile phone application’, Progress In Electromagnetics Research B, Vol. 14, 127-148, 2009.

[7] Seif Naoui, Lassaad Latrach, and Ali Gharsallah, "Metamaterials Dipole Antenna by Using Split Ring Resonators for RFID Technology", Microwave and Optical Technology Letters, Vol.56: pp.2899-2903, 2014; DOI 10.1002/mop.28731.

[8] W.-J. Liao, T.-M. Liu and S.-Y. Ho, “Miniaturized PIFA Antenna for $2.4 \mathrm{GHz}$ ISM Band Applications," IEEE Proceedings of the 6th European Conference on Antennas and Propagation (EUCAP), Prague, 26-30, pp. 3034-3037n, March 2012.

[9] Gil, I. ; Fernandez-Garcia, R. "Analysis of PIFA antenna coupling in nearby traces and reduction with CSRRs in PCB at 2.45 GHz" Electromagnetic Compatibility (EMC), 2015 IEEE International Symposium on, Page(s): 361 - 365.

[10] S. C. Basaran and E. Dokuzlar, " A Frequency Reconfigurable PIFA Design for Wireless Communication Applications" PIERS Proceedings, Prague, Czech Republic, July 6\{9, 2015, pages 118-121.

[11] Loutridis, A. John, M. \& Ammann, M.J. "Dual Band LTE Planar Inverted-F Antnna for M2M Applications", Microwave and Optical Technology Letters, vol. 55, issue 12, pp. 2925-2929, DOI: 10.1002/mop.27980, 2013.

[12] Gabriel, S., R.W. Lau and C. Gabriel, 1996. The dielectric properties of biological tissues: III. Parametric models for the dielectric spectrum of tissues. Phys. Med. Biol., 41: 2271-2293. DOI: 10.1088/0031-9155/41/11/003

[13] Constantine A. Balanis, “Antenna Theory : Analysis and Design”, 3rd edn, John Wiley \& Sons, Ltd, Chichester, ISBN: 978-0-471-66782-7,1136 pages, May 2005. 